\title{
The anti-vascular endothelial growth factor receptor-1 monoclonal antibody D16F7 inhibits invasiveness of human glioblastoma and glioblastoma stem cells
}

Maria Grazia Atzori ${ }^{1}$, Lucio Tentori ${ }^{1}$, Federica Ruffini ${ }^{2}$, Claudia Ceci ${ }^{1}$, Lucia Lisi ${ }^{3}$, Elena Bonanno ${ }^{4}$, Manuel Scimeca ${ }^{4}$, Eskil Eskilsson ${ }^{5}$, Thomas Daubon ${ }^{6,7}$, Hrvoje Miletic ${ }^{7}$, Lucia Ricci Vitiani ${ }^{8}$, Roberto Pallini ${ }^{9}$, Pierluigi Navarra ${ }^{3,10}$, Rolf Bjerkvig ${ }^{7}$, Stefania D'Atri ${ }^{2}$, Pedro Miguel Lacal ${ }^{2^{*}}$ and Grazia Graziani ${ }^{{ }^{*}}$

\begin{abstract}
Background: Glioblastoma (GBM) is a highly migratory, invasive, and angiogenic brain tumor. Like vascular endothelial growth factor-A (VEGF-A), placental growth factor (PIGF) promotes GBM angiogenesis. VEGF-A is a ligand for both VEGF receptor-1 (VEGFR-1) and VEGFR-2, while PIGF interacts exclusively with VEGFR-1. We recently generated the novel anti-VEGFR-1 monoclonal antibody (mAb) D16F7 that diminishes VEGFR-1 homodimerization/ activation without affecting VEGF-A and PIGF binding.

Methods: In the present study, we evaluated the expression of VEGFR-1 in human GBM tissue samples $(n=42)$ by immunohistochemistry, in cell lines $(n=6)$ and GBM stem cells (GSCs) $(n=18)$ by qRT-PCR and/or western blot analysis. In VEGFR-1 positive GBM or GSCs we also analyzed the ability of D16F7 to inhibit GBM invasiveness in response to VEGF-A and PIGF.

Results: Most of GBM specimens stained positively for VEGFR-1 and all but one GBM cell lines expressed VEGFR-1. On the other hand, in GSCs the expression of the receptor was heterogeneous. D16F7 reduced migration and invasion of VEGFR-1 positive GBM cell lines and patient-derived GSCS in response to VEGF-A and PIGF. Interestingly, this effect was also observed in VEGFR-1 positive GSCs transfected to over-express wild-type EGFR (EGFRwt ${ }^{+}$) or mutant EGFR (ligand binding domain-deficient EGFRvIII+). Furthermore, D16F7 suppressed intracellular signal transduction in VEGFR-1 over-expressing GBM cells by reducing receptor auto-phosphorylation at tyrosine 1213 and downstream Erk1/2 activation induced by receptor ligands.
\end{abstract}

Conclusion: The results from this study suggest that VEGFR-1 is a relevant target for GBM therapy and that D16F7derived humanized mAbs warrant further investigation.

Keywords: VEGFR-1, PIGF, VEGF-A, Glioblastoma, Angiogenesis, Molecular marker, Molecular medicine

\footnotetext{
*Correspondence: p.lacal@idi.it; graziani@uniroma2.it

Maria Grazia Atzori and Lucio Tentori are equal first authors.

Pedro Miguel Lacal and Grazia Graziani are equal last authors.

${ }^{2}$ Laboratory of Molecular Oncology, "Istituto Dermopatico

dell'Immacolata"-IRCCS, Via dei Monti di Creta, 104, 00167 Rome, Italy

'Department of Systems Medicine, University of Rome Tor Vergata, Via

Montpellier 1, 00133 Rome, Italy

Full list of author information is available at the end of the article
} 


\section{Background}

Vascular endothelial growth factor receptor-1 (VEGFR-1) is a high-affinity tyrosine kinase receptor for VEGF-A, VEGF$\mathrm{B}$, and placental growth factor (PlGF) ligands $[1,2]$. VEGFR-1 is composed of seven extracellular immunoglobulin homology domains, a single transmembrane region, and an intracellular tyrosine kinase domain. The interaction of VEGFR-1 with its ligands induces receptor dimerization, tyrosine auto-phosphorylation, transphosphorylation, and docking of signaling proteins [1-3]. VEGFR-1 also exists as soluble form that acts as decoy receptor preventing VEGF$\mathrm{A}$ and PlGF interaction with transmembrane receptors [3]. While VEGFR-1 does not play a relevant role in physiological angiogenesis in the adult, this receptor is indeed important in tumor angiogenesis and directly activates signaling pathways crucial for tumor growth, progression, and metastasis in cancer cells $[4,5]$.

VEGF-A binds to both VEGFR-1 and VEGFR-2, while VEGF-B and PlGF interact exclusively with VEGFR-1. VEGF-A is the most widely studied angiogenic factor, and its role in tumor angiogenesis via stimulation of VEGFRs expressed on tumor endothelium is well established [6]. It also directly interacts with VEGFRs expressed on cancer cells stimulating disease progression. In its homo- or heterodimeric form with PlGF, VEGF-A may activate VEGFR-1 and VEGFR-2 homo- or heterodimers [7, 8]. PIGF binds to VEGFR-1 with higher or lower affinity compared with VEGF-B or VEGF-A, respectively [4, 9]. VEGF-B role in tumor biology appears limited [10], while PlGF seems to have an important disease-associated role because its expression, which is low or undetectable in most adult healthy tissues, is significantly up-regulated in a number of pathological conditions including cancer [5]. Interestingly, PlGF is produced by tumor, endothelial, and other cells of the tumor stroma including inflammatory cells promoting migration, proliferation, and survival $[11,12]$. Moreover, high tumor expression levels are associated with a poor prognosis [11, 12].

VEGFR-1 is expressed in endothelial cells during vessel formation and remodeling, macrophages, myoepithelial cells, and a variety of human cancer cells, favoring cell migration and survival $[1,2]$. In tumors, VEGFR-1 signaling inhibits apoptosis, induces chemoresistance, and predicts poor prognosis and recurrence $[1,13,14]$. Moreover, it is involved in the mobilization of myeloid bone marrow-derived cells that generate tumorassociated macrophages $[1,15]$. VEGF-A and PIGF binding to VEGFR-1 can induce phosphorylation and activation of mitogen-activated protein kinases (MAPKs) Erk1/2 and p38 [16], and through VEGFR-1 activation, PIGF also stimulates the trans-phosphorylation of specific VEGFR-2 tyrosine residues [17]. Interestingly, it has been proposed that PIGF may enhance tumor cell invasiveness by augmenting matrix metalloproteinase (MMP) secretion via Erk1/2 signaling [18].

A number of studies have been designed to disrupt tumor angiogenesis and growth by anti-VEGF-A and anti-VEGFR-2 monoclonal antibodies (mAbs) or VEGFRs small molecule tyrosine kinase inhibitors. We hypothesize that molecules selectively targeting VEGFR1 may inhibit tumor vascularization and invasion/metastasis while producing lower systemic toxicity than agents directed against VEGF-A or VEGFR-2, which cause adverse effects due to inhibition of physiological angiogenesis [19]. Therefore, we have generated an anti-VEGFR-1 mAb (D16F7) by immunizing mice with a peptide corresponding to amino acids 149-161 of human VEGFR-1 [15]. While not affecting binding of VEGF-A and PlGF, D16F7 reduces VEGFR-1 homodimerization and activation by both ligands. This mAb inhibits chemotaxis of human endothelial, myelomonocytic, and melanoma cells in response to VEGFR-1 ligands. In an in vivo murine model, D16F7 is well tolerated, inhibits angiogenesis in response to inflammatory stimuli and markedly affects melanoma growth. The antitumor effect is associated with tumor cell apoptosis, vascular abnormalities, reduced monocyte/macrophage infiltration and impaired myeloid progenitor mobilization [15].

In the present study we investigated whether D16F7 exerts inhibitory activity against human glioblastoma (GBM), which is a highly aggressive brain tumor that relies on angiogenesis for growth and histological progression $[20,21]$. The standard care of newly diagnosed GBM includes surgical tumor resection followed by radiation therapy and chemotherapy with the alkylating agent temozolomide [22, 23]. GBM exhibits a highly abnormal blood supply, which leads to swelling and reduced blood perfusion within the tumor and causes it to become resistant to chemo- and radiotherapy. VEGF-A and PlGF expression by glioma cells additionally induces accumulation of VEGFR-1-positive bone marrow-derived myeloid cells in the tumor tissue [24]. While anti-VEGF-A treatment has become part of standard post-surgical treatment for recurrent GBM, its beneficial effects are temporary and it does not effectively extend patient overall survival [25].

In this context, our results demonstrate that D16F7 markedly inhibits chemotaxis and invasiveness of GBM cells and patient-derived GBM stem cells (GSCs) in response to VEGF-A and PlGF, suggesting that VEGFR-1 might represent a suitable target that deserves further investigation for GBM treatment.

\section{Methods}

Immunohistochemical analysis of VEGFR-1 in tissue samples from GBM patients

We enrolled 42 adults [mean age 60.51 (34-79), 27 males/ 15 females], who underwent surgery for primary GBM 
at the Institute of Neurosurgery, "Università Cattolica del Sacro Cuore" (Rome, Italy), from March 2005 to September 2011. Diagnosis of GBM was established on histological examination according to the WHO classification (grade IV) of tumors of the nervous system. All patients provided written consent to use their specimens for research and the research proposal was approved by the university Ethical Committee. Tissues were fixed in $4 \%$ paraformaldehyde in $0.1 \mathrm{M}$ phosphate buffer $\mathrm{pH} 7.6$ at $4{ }^{\circ} \mathrm{C}$ overnight. Tissues were rehydrated in graded ethanol solutions, xylene and finally embedded in Paraplast Plus (Tyco/Healthcare, Mansfield, MA). Sections, 3-4 $\mu \mathrm{m}$ thick, were deparaffinized and incubated in $10 \mathrm{mM}$ citrate buffer, $\mathrm{pH}$ 6.0, dry heated for 10 min each to unmask antigen sites, cooled and washed in phosphate-buffered saline (PBS). Endogenous peroxidase activity was inhibited by rinsing the slides in $3 \%$ hydrogen peroxide for $5 \mathrm{~min}$. Nonspecific binding was blocked by $5 \mathrm{~min}$ incubation with the Super Block Solution (ScyTek Laboratories, UT). After washing in PBS, sections were incubated for $10 \mathrm{~min}$ at room temperature with rabbit anti-Human Flt-1/VEGFR-1 polyclonal antibody (1:50; Spring Bioscience, Pleasanton, CA). The immunostaining conditions were standardized using human placenta as positive control (data not shown). Sections were washed extensively with PBS and subsequently processed using the Ultra Tek Anti-Polyvalent kit (ScyTek Laboratories). Finally sections were treated with 3,3'-diaminobenzidine as chromogen, contrasted with hematoxylin and mounted [26]. Two blinded examiners evaluated staining of human tumor specimens. For each specimen, the number of VEGFR-1 positive cells in total 50 cells was counted.

\section{Cell lines and culture conditions}

The human GBM cell lines A172, U87, LN18, T98G and U373 were from American Type Culture Collection (ATCC, Manassas, VA). Cells were maintained in DMEM (Sigma-Aldrich, St. Louis, MO) supplemented with $10 \%$ fetal bovine serum (FBS, Sigma-Aldrich), $2 \mathrm{mM}$ L-glutamine, 100 units/ml penicillin, and $100 \mu \mathrm{g} /$ $\mathrm{ml}$ streptomycin sulfate, at $37{ }^{\circ} \mathrm{C}$ in a $5 \% \mathrm{CO}_{2}$ humidified atmosphere.

GSCs were isolated from 18 surgical samples of adult patients who had undergone craniotomy at the Institute of Neurosurgery, "Università Cattolica del Sacro Cuore" (Rome, Italy). Prior to surgery all patients provided written informed consent according to the Declaration of Helsinki and the research proposal was approved by the university Ethical Committee. In regard to GSCs origin, the diagnosis of GBM was established on histological examination according to the WHO classification (grade IV) of tumors of the nervous system. Tumor samples were subjected to mechanical dissociation. The resulting cell suspension was cultured in a serum-free medium supplemented with $20 \mathrm{ng} / \mathrm{ml}$ epidermal growth factor (EGF) and $10 \mathrm{ng} / \mathrm{ml} \mathrm{FGF-2} \mathrm{(PeproTech,} \mathrm{Rocky} \mathrm{Hill,} \mathrm{NJ).}$ Generation of GSCs was defined by the following criteria: in vitro formation of primary neurospheres expressing stem cell markers such as CD133, SOX2, Musashi-1 and nestin, capacity of self-renew, ability to co-express astrocytic as well as neuronal phenotypic markers after serum-induced differentiation in vitro [27-29]. GSCs were characterized by immunofluorescence analysis as previously described [30]. All the GSC lines tested in this study were positive for SOX2, Musashi-1 and nestin, whereas they expressed different levels of CD133 (data not shown).

P3, EGFRwt ${ }^{+}$, and EGFRvIII ${ }^{+}$GSC lines were previously described [31]. Cells were cultured in neurobasal medium (NBM) supplemented with $2 \mathrm{mM}$ GlutaMAX and 1× B-27 (Life Technologies, Carlsbad, CA), 1× penicillin/streptomycin (Lonza, Basel, Switzerland), $1 \mathrm{U} / \mathrm{ml}$ heparin (Sigma-Aldrich) and $20 \mathrm{ng} / \mathrm{ml} \mathrm{FGF-2} \mathrm{(hereafter}$ referred to as complete NBM).

The human umbilical vascular endothelial cells (HUVEC) were isolated from freshly delivered umbilical cords as previously described [32] and cultured in EGM-2.

The human GR-Mel and M14 melanoma cell lines, used as positive and negative controls for VEGFR-1 or VEGFR-2 transcripts, were obtained and cultured as previously described [33].

Human GBM cell lines were authenticated by STR profiling (BMR genomics, Padova, Italy) and GSCs lines were periodically tested for the expression of phenotypic markers [in P3-derived cells, EGFR amplification or mutation; in GSCs, the above described markers].

\section{Generation of GBM cell lines overexpressing VEGFR-1}

Cell clones were obtained by limiting dilution from U87 cells and one clone was transfected with the pBLAS49.2 or pBLAS49.2/VEGFR-1 plasmids. The pBLAS49.2/ VEGFR-1 construct was obtained by cloning of VEGFR-1 cDNA from pcDNA3/VEGFR-1 plasmid (a generous gift of Dr. K. Ballmer-Hofer, PSI, Zurich) into pBLAS49.2 vector (InvivoGen, San Diego, CA). Transfection was performed using lipofectamine 2000 (Invitrogen, Camarillo, CA), as described by the manufacturer, and transfected cells were selected in blasticidine (Invitrogen) containing culture medium. Antibiotic resistant clones were isolated by ring cloning and U87 clones maintained in the presence of $2.5 \mu \mathrm{g} / \mathrm{ml}$ blasticidine. VEGFR-1 expressing subclones were identified by RT-PCR and Western blotting.

\section{Analysis of VEGFRs transcripts}

Quantification of membrane VEGFR-1 and VEGFR-2 transcripts was performed by quantitative real-time reverse transcriptase -polymerase chain reaction (qRT-PCR) 
according to the dual-labeled fluorigenic probe method and using an ABI Prism 7000 sequence detector (PerkinElmer, Groningen, the Netherlands), as previously described [34]. Expression levels were calculated by the relative standard curve method. Primers used were as follows: VEGFR-1, forward $5{ }^{\prime}$-ACCGAATGCCACC TCCATG-3' and reverse 5'-AGGCCTTGGGTTTGCT GTC-3'; VEGFR-2, forward 5'-GTCTATGCCATTCC TCCCCC-3' and reverse $5^{\prime}$-GAGACAGCTTGGCT GGGCT-3'. For each sample, the level of VEGFR-1 or VEGFR-2 transcripts was normalized to that of $18 \mathrm{~S}$ RNA (TaqMan ${ }^{\circ}$ Gene Expression Assay, Applied Biosystems, Foster City, CA) and referred to the values of the VEGFR-1 and VEGFR-2 negative M14 cell line, to which the arbitrary value of 1 was assigned.

In VEGFR-1-transfected cells detection of VEGFR-1 transcript was confirmed by RT-PCR analysis. The cDNA preparation followed by PCR amplification to evaluate VEGFR-1 expression was performed as previously described [35], utilizing an annealing temperature of $58{ }^{\circ} \mathrm{C}$ and the following primers: human VEGFR-1, forward primer 5'-CTCCTGAGTACTCTACTCCT-3', reverse primer 5'-GAGTACAGGACCACCGAGTT-3' (640 bp fragment); human glyceraldehyde-3-phosphate dehydrogenase (GAPDH), forward primer 5 '-TCCCAT CACCATCTTCCA-3', reverse primer 5' -CATCACGC CACAGTTTCC-3' (380 bp fragment).

\section{Quantification of VEGF-A and PIGF in GBM cell culture conditioned media by ELISA}

Conditioned media from GBM cells were obtained by incubating semi-confluent cultures for $24 \mathrm{~h}$ in $0.1 \% \mathrm{BSA} /$ DMEM medium without FBS. These conditions did not significantly affect cell viability. Supernatants were concentrated at least 10-fold in Centriplus concentrators (Amicon, Beverly, MA). Cells were detached from the flasks with PBS/EDTA. Cytokine secretion values were normalized by the total number of cells.

Quantification of the amount of VEGF-A and PlGF in the conditioned medium was performed using goat antiVEGF-A or anti-PlGF IgGs (R\&D Systems, Abingdon, $\mathrm{UK})$, at a concentration of $10 \mu \mathrm{g} / \mathrm{ml}$ in PBS, to coat Maxisorp Nunc immunoplates (Nunc, Roskilde, Denmark). Detection of the cytokines was performed with biotinylated goat anti-VEGF or anti-PlGF IgGs $(0.4 \mu \mathrm{g} / \mathrm{ml}$; R\&D Systems) followed by incubation with streptavidin alkaline phosphatase conjugate $(1: 10,000)$ (Roche, Monza, Italy) and alkaline phosphatase reaction. Optical density at $405 \mathrm{~nm}$ was measured in a 3550-UV Microplate reader (Bio-Rad, Hercules, CA).

\section{Western blotting}

Proteins were run in 10\% SDS-polyacrylamide gels and transferred to supported nitrocellulose membranes by standard techniques. Immunodetection was performed using the following antibodies: mouse monoclonal antiVEGFR-1 (clone D2, 1:500; Santa Cruz Biotechnology, Santa Cruz, CA); mouse monoclonal anti-EGF receptor (EGFR) (528, 1:1000; Santa Cruz Biotechnology); mouse monoclonal antibody anti-EGFRvIII (L8A4; 1:1000; Absolute Antibody, Oxford, UK); rabbit polyclonal antiphosphorylated VEGFR-1 at tyrosine 1213 (1:500; R\&D Systems); rabbit polyclonal anti-Erk1\&2 (1:1000; Genetex, Irvine, CA); rabbit polyclonal anti-phospho-Erk1\&2 (Thr/Tyr185/187, 1:1000; Invitrogen); or rabbit polyclonal anti- $\beta$-actin (1:10,000; Sigma Aldrich) primary antibodies. Anti-mouse or anti-rabbit Ig/Horseradish peroxidase secondary antibodies and ECL Western blotting detection reagents from GE Healthcare (Milan, Italy) were used to identify the proteins of interest.

\section{Chemotaxis assay and spheroid invasion assay}

In vitro migration assay was performed using Boyden chambers equipped with $8 \mu \mathrm{m}$ pore diameter polycarbonate filters (Nuclepore, Whatman Incorporated, Clifton, NJ) coated with $5 \mu \mathrm{g} / \mathrm{ml}$ gelatin (Sigma-Aldrich), as previously described [36, 37]. Treatment with D16F7 was carried out by incubating the cells in the presence of the indicated $\mathrm{mAb}$ concentrations in a rotating wheel for $30 \mathrm{~min}$ at room temperature. Cells $\left(2 \times 10^{5} /\right.$ chamber $)$ were then loaded in the upper compartment of Boyden chambers and migration assay, toward stimuli $(50 \mathrm{ng} / \mathrm{ml}$ VEGF-A or PIGF) present in the lower compartment, was done in the absence or in the presence of D16F7 $\mathrm{mAb}$ or, in selected experiments, of an equivalent amount of a species- and isotype-matched control antibody (mouse IgG1, R\&D Systems) for $18 \mathrm{~h}$. Migrated cells, attached to the lower side of the filters, were stained with crystal violet counted in triplicate samples for a total of 12 high power (200× magnification) microscopic fields.

For spheroid invasion assay, tumor cells $(25,000-$ 30,000 cells $/ \mathrm{ml}$ ) were suspended in DMEM-1640 containing 10\% FBS (for GBM cell lines) or in complete NBM (for P3-derived GSC lines), supplemented with methyl cellulose $(0.24 \%$ final concentration; SigmaAldrich), seeded in 96-well round bottom cell culture plates $\left(100 \mu \mathrm{l} /\right.$ well; Corning ${ }^{\bullet}$ Costar $^{\circ}$ Ultra-Low attachment multi-well, Sigma-Aldrich) and centrifuged at $3000 \mathrm{rpm}$ for $90 \mathrm{~min}$ [31]. Plates were then incubated for $24 \mathrm{~h}$ under standard culture conditions $\left(5 \% \mathrm{CO}_{2}\right.$, at $37{ }^{\circ} \mathrm{C}$ ) to allow spheroid formation. Spheroids were collected, embedded individually in $100 \mu \mathrm{l}$ of matrigel (reduced growth factor basement membrane matrix, Pathclear, Cultrex, Gaithersburg, MD) in $0.1 \%$ BSA/ DMEM or NBM medium, with or without VEGF-A or PlGF (50 ng/ml) and/or D16F7 mAb, and plated in each well of a 96-well flat bottom plate, previously coated 
with $50 \mu \mathrm{l}$ of matrigel. Five to ten replicates were set up for each experimental group. After matrigel solidification at $37{ }^{\circ} \mathrm{C}, 100 \mu \mathrm{l}$ of invasion medium, with or without VEGF-A, PlGF or EGF (50 ng/ml), were added and plates incubated at $37{ }^{\circ} \mathrm{C}$ for up to $72 \mathrm{~h}$. Spheroids were visualized and photographed using a Nikon Eclipse TS100 microscope in conjunction with a Nikon DS-Fi1 high resolution camera (Melville, NY). Measurements were performed using Adobe Photoshop CS6 software. Relative invasion area was defined as area of spheroids (in $\mathrm{mm}^{2}$ ) at each time point minus area on day 0 .

Preliminary experiments on U87 and U87-MF24 cell migration in response to PlGF and in the presence of graded concentrations of D16F7 indicated that the $\mathrm{IC}_{50}$ values were $1.54 \pm 0.22 \mu \mathrm{g} / \mathrm{ml}$ and $2.49 \pm 0.56 \mu \mathrm{g} / \mathrm{ml}$, respectively. Therefore, based on these results we selected the mAb concentrations to be tested in the functional assays.

\section{Cell proliferation assay}

Cell proliferation was evaluated in 96-well plates using the tetrazolium compound MTS [3-(4,5-dimethylthiazol2-yl)-5-(3-carboxymethoxyphenyl) 2-(4-sulphophenyl)$2 \mathrm{H}$-tetrazolium, inner salt] from Promega (Madison, WI), as previously described [38]. Briefly, increasing numbers of GBM cells, suspended in complete medium containing graded concentrations of D16F7 up to $20 \mu \mathrm{g} / \mathrm{ml}$ of D16F7 or control antibody or without antibodies, were dispensed into flat-bottom 96-well plates and grown at $37{ }^{\circ} \mathrm{C}$ in a $5 \% \mathrm{CO}_{2}$ humidified atmosphere. Six replica wells were used for every condition. After 3 days, $20 \mu \mathrm{l}$ of MTS solution were added to each well and cells were incubated at $37^{\circ} \mathrm{C}$ for $2 \mathrm{~h}$. Absorbance was read at $490 \mathrm{~nm}$ (reference wavelength $655 \mathrm{~nm}$ ) using a 3550-UV Microplate reader (Bio-Rad).

\section{Statistical analyses}

Statistical analysis of the differences between pairs of groups was performed by Student's $t$ test. For multiple comparisons ANOVA analysis, followed by Bonferroni's post-test, was used. Statistical significance was determined at $\alpha=0.05$ level. Differences were considered statistically significant when $p<0.05$.

\section{Results}

\section{Analysis of VEGFR-1 in patient-derived GBM specimens and cell lines}

To investigate the relevance of VEGFR-1 in GBM, we initially investigated the expression of VEGFR-1 by immunohistochemistry in tissue specimens obtained from 42 adult GBM patients (Table 1). Most of GBM tissue samples showed a significant VEGFR-1 immunoreactivity. VEGFR-1 staining was observed in association with GBM cells as well as with endothelial cells (Table 1 and Additional file 1: Figure S1 and Additional file 2: Figure S2) in accordance with previous studies [39, 40].

With the purpose of analyzing the effect of the anti-VEGFR-1 D16F7 mAb in GBM models, a set of human GBM cell lines was characterized for the expression of membrane VEGFRs and production of VEGFR-1 ligands. The VEGFR-1 mRNA, evaluated by qRT-PCR, was detected in five out of six cell lines (Fig. 1a, upper panel), even though at lower levels compared with the positive control HUVEC. In the same analysis, VEGFR-2 mRNA was observed in all cell lines, although in most of them at a lower level with respect to VEGFR-1 (Fig. 1a, lower panel). ELISA analysis of PIGF and VEGF-A secretion in culture supernatants collected from the different GBM cell lines revealed that: a) PlGF was produced by most of the cell lines tested and was nearly undetectable in T98G cells (Fig. 1b, upper panel), and b) all cell lines secreted substantial amounts of VEGF-A (Fig. 1b, lower panel).

\section{The anti-VEGFR-1 D16F7 mAb inhibits GBM cell migration and extracellular matrix (ECM) invasion in response to VEGF-A and PIGF}

Activation of VEGFR-1 is involved in endothelial and monocytic cell migration, and PIGF has a role in controlling cell motility and invasiveness of cultured cancer cells [3]. In this regard, we recently demonstrated that the anti-VEGFR-1 D16F7 mAb inhibits human melanoma chemotaxis in response to PlGF [15]. The influence of D16F7 on GBM migratory response to VEGF-A and PlGF was tested using VEGFR-1-positive U87 and LN18 cells in Boyden chambers containing gelatin coated filters. VEGF-A and PIGF stimulated substantial chemotaxis of U87 cells, and pre-incubation with D16F7 markedly reduced ligand-induced migration (Fig. 1c). On the other hand, a murine IgG1 control did not affect migration of U87 cells upon stimulation of VEGFR-1 (Additional file 3: Figure S3), in accordance with a previous study with melanoma cells [15]. These data indicated a prevalent role for VEGFR-1 in the promotion of GBM cell migration compared to VEGFR-2, even when VEGF-A was used as stimulus. The anti-VEGFR-1 mAb also inhibited the migratory response of LN18 cells (data not shown). The influence of D16F7 on VEGF-A and PIGFinduced chemotaxis of other VEGFR-1 positive cell lines (i.e., A172 and T98G) could not be tested in this assay because cells failed to adhere to gelatin-coated filters. Therefore, the ability of D16F7 to reduce ECM invasion of A172 cells was tested by a spheroid invasion assay. The VEGFR-1-selective ligand PIGF stimulated matrigel-embedded spheroids to markedly invade the 
Table 1 Characteristics and VEGFR-1 expression of GBMs from which tissue specimens were derived

\begin{tabular}{|c|c|c|c|c|}
\hline GBM patient & Tumor location & Primary $(\mathrm{P})$ Recurrent $(\mathrm{R})$ & Overall Survival (months) & VEGFR-1 ${ }^{\text {a }}$ \\
\hline 1 & NA & $P$ & 13 & +++ \\
\hline 2 & Temporal & $P$ & 19 & + \\
\hline 3 & Temporal & $\mathrm{P}$ & 60 & - \\
\hline 4 & Frontal & $\mathrm{R}$ & $N A^{b}$ & ++ \\
\hline 5 & Frontal & $P$ & 7 & +++ \\
\hline 6 & NA & $P$ & NA & +++ \\
\hline 7 & Frontal & $P$ & 15 & +++ \\
\hline 8 & Frontal & $P$ & 2 & +++ \\
\hline 9 & Temporal & $P$ & 4 & +++ \\
\hline 10 & Occipital & $\mathrm{P}$ & 33 & + \\
\hline 11 & Temporal & $P$ & 14 & - \\
\hline 12 & NA & $P$ & NA & + \\
\hline 13 & NA & $\mathrm{R}$ & NA & + \\
\hline 14 & Temporal & $P$ & 53 & + \\
\hline 15 & Parietal & $P$ & 53 & + \\
\hline 16 & NA & P & 9 & +++ \\
\hline 17 & Frontal & $P$ & NA & + \\
\hline 18 & Frontal & $P$ & NA & +++ \\
\hline 19 & Tempo-Parietal & R & 53 & +++ \\
\hline 20 & Temporal & $P$ & NA & +++ \\
\hline 21 & NA & $P$ & NA & +++ \\
\hline 22 & Temporal & $\mathrm{P}$ & NA & + \\
\hline 23 & Parietal & $\mathrm{P}$ & 6 & +++ \\
\hline 24 & NA & P & NA & ++ \\
\hline 25 & Temporal & $P$ & NA & +++ \\
\hline 26 & NA & $\mathrm{R}$ & NA & + \\
\hline 27 & Frontal & $\mathrm{R}$ & NA & + \\
\hline 28 & Occipital & P & NA & +++ \\
\hline 29 & NA & $\mathrm{P}$ & NA & +++ \\
\hline 30 & Temporal & $P$ & NA & +++ \\
\hline 31 & NA & P & NA & ++ \\
\hline 32 & Temporal & P & NA & +++ \\
\hline 33 & Temporal & $P$ & 6 & + \\
\hline 34 & NA & $\mathrm{P}$ & NA & +++ \\
\hline 35 & Frontal & $P$ & 12 & + \\
\hline 36 & Fronto-Temporal & P & NA & ++ \\
\hline 37 & Occipital & $P$ & 8 & +++ \\
\hline 38 & Frontal & $P$ & NA & $-1+$ \\
\hline 39 & Temporal & $P$ & NA & +++ \\
\hline 40 & NA & P & 38 & $-/+$ \\
\hline 41 & NA & $\mathrm{R}$ & 24 & ++ \\
\hline 42 & Frontal & P & 12 & + \\
\hline
\end{tabular}

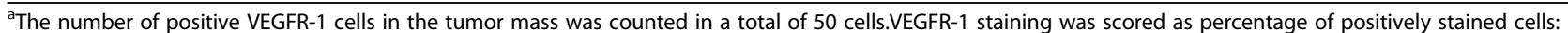
,$-<10 \% ;-/+, 11-25 \%$; +, 26-50\%; ++, 51-75\%; +++, >75\%

${ }^{\mathrm{b}} \mathrm{NA}$ : not available 

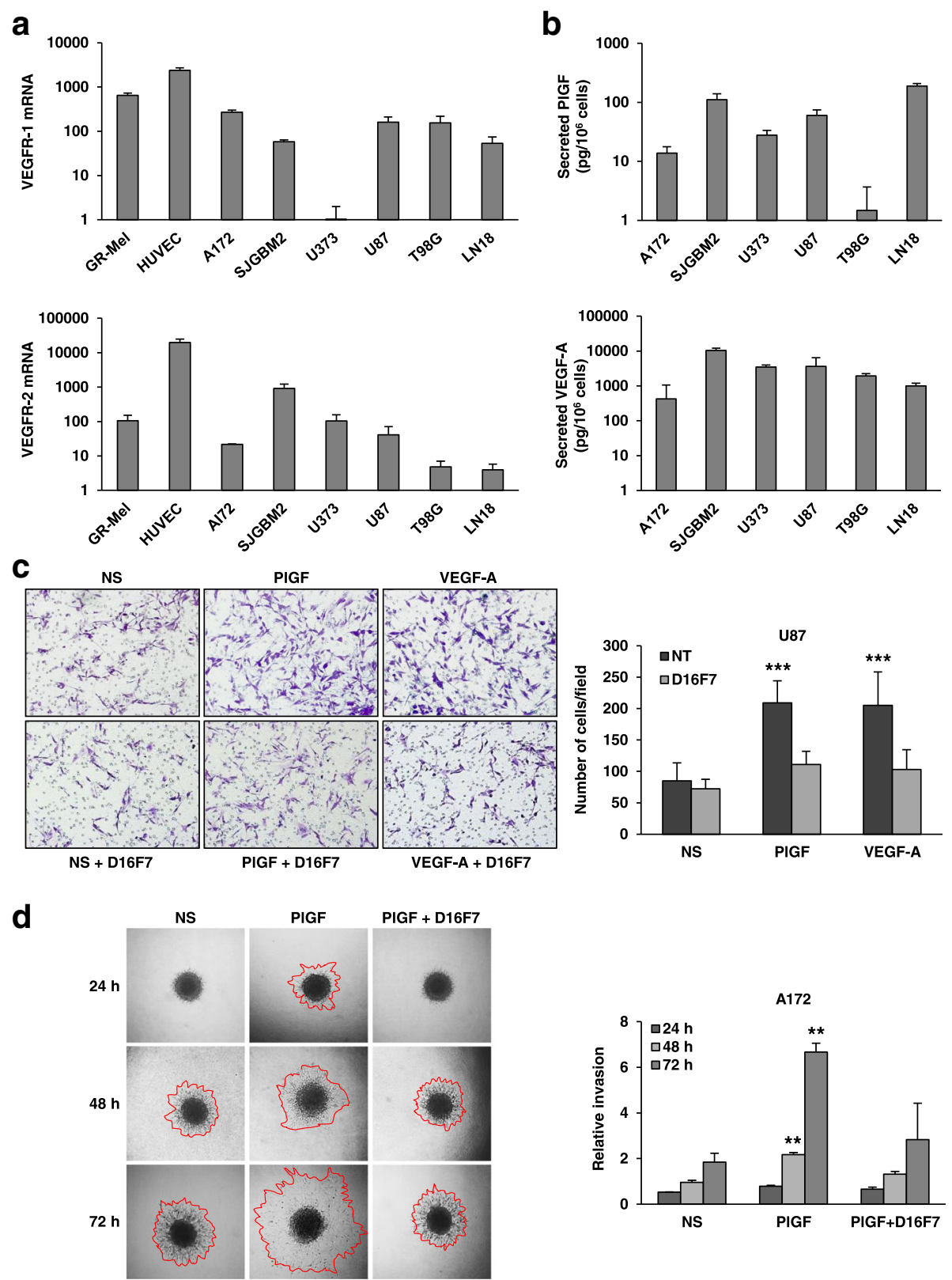

Fig. 1 D16F7 inhibitory effects on VEGF-A or PIGF-induced migration and ECM invasion in human GBM cells expressing VEGFR-1. a Detection of VEGFR-1 and VEGFR-2 transcripts in GBM cell lines was performed by qRT-PCR. Results indicate relative mRNA expression and are the mean \pm SD of three independent determinations. b PIGF and VEGF-A secretion was quantified by ELISA (mean \pm SD, $n=3$ ). c Migration of U87 cells in response to PIGF or VEGF-A was evaluated in the absence (not treated, NT) or presence of $5 \mu \mathrm{g} / \mathrm{ml} \mathrm{D16F7;} \mathrm{NS,} \mathrm{non-stimulated} \mathrm{cells.} \mathrm{Representative} \mathrm{photographs} \mathrm{of}$ U87 cells are shown (100x magnification). Histograms represent the mean $\pm \mathrm{SD}(n=3)$ of migrated cells/microscopic field. Results of statistical analysis using one-way ANOVA, followed by Bonferroni's post-test were as follows: PIGF vs NS, PIGF vs D16F7 or PIGF vs PIGF + D16F7 and VEGF-A vs NS, VEGFA vs D16F7 or VEGF-A vs VEGF-A + D16F7, $p<0.001$ (**); differences between NS, D16F7, PIGF + D16F7 or VEGF-A + D16F7 were not significant. d For spheroid invasion assay A172 cells were embedded in matrigel in the absence or presence of D16F7 $(10 \mu \mathrm{g} / \mathrm{ml})$ and PIGF $(50 \mathrm{ng} / \mathrm{ml})$. Representative pictures of spheroids taken at 24, 48 and $72 \mathrm{~h}$ after embedding cells in matrigel (40X magnification) are shown. NS, non-stimulated cells. Relative invasion was quantified as spheroid area difference (in $\mathrm{mm}^{2}$ ) at each of the indicated time points minus day 0 . Data are expressed as mean \pm SD of triplicate samples and results of statistical analysis were as follows: PIGF vs NS and PIGF vs PIGF + D16F7 at 48 and $72 h, p<0.01$ (**). Differences between NS and PIGF + D16F7 were not significant

surrounding matrix in a time-dependent manner, and D16F7 significantly reduced GBM cell invasiveness (Fig. 1d). Notably, D16F7 at the concentrations tested in the chemotaxis and invasion assays did not inhibit proliferation in vitro in any of the GBM cell lines tested (data not shown). 
The anti-VEGFR-1 D16F7 mAb inhibits migration of VEGFR-1 positive human GSCs in response to VEGF-A and PIGF

GBMs harbor a subset of GBM stem-like cells (GSCs) which are radioresistant and chemoresistant, participate in tumor neovascularization, and promote tumor recurrence $[30,41]$. To assess whether VEGFR-1 plays a role in the aggressive behavior of this GBM cell subset, 18 patient-derived GSC lines (Table 2) were analyzed for VEGFR-1 and VEGFR-2 expression by qRT-PCR. VEGFR-1 expression was quite heterogeneous, while all GSC lines were weakly positive for VEGFR-2 (Fig. 2a). VEGFR-1 expression was verified by Western blotting (Fig. 2b) in GSCs expressing the greatest levels of VEGFR-1 transcript. VEGFR-1 positive GSC lines \#213, \#169 and \#74 migrated in response to both VEGF-A and PlGF, and treatment with D16F7 reverted ligand-induced chemotaxis (Fig. 2c and d).

Mutation/amplification of EGFR has been reported in a wide proportion of GBMs. In fact, a large-scale sequencing study indicated that $57 \%$ of GBM patient samples contain mutation, rearrangement, altered splicing, and/or focal amplification of EGFR and that various mutations often co-occur with EGFR rearrangement and/or amplification [42]. In this context, we next investigated the influence of D16F7 mAb in a patient-derived GSC line (P3) modified to over-express wild-type EGFR $\left(\right.$ EGFRwt ${ }^{+}$) or mutant EGFR (ligand binding domain-

Table 2 Characteristics of the original GBMs from which GSCS were derived

\begin{tabular}{lllll}
\hline GSC line & Tumor location & $\begin{array}{l}\text { Primary (P) } \\
\text { Recurrent (R) }\end{array}$ & $\begin{array}{l}\text { Overall survival } \\
\text { (months) }\end{array}$ & EGFRvIII \\
\hline$\# 1$ & Temporal & P & 12,5 & Neg \\
$\# 30$ & Frontal & P & 7,5 & Pos \\
$\# 61$ & Occipital & P & 6,0 & Pos \\
$\# 62$ & Frontal & R & 14,0 & Neg \\
$\# 74$ & Frontal & P & 8,0 & Pos \\
$\# 76$ & Frontal & P & 42,0 & Neg \\
$\# 83$ & Temporal & P & 8,0 & Pos \\
$\# 120$ & Parietal & R & 16,5 & Neg \\
$\# 144$ & Temporal & P & 26,0 & Pos \\
$\# 148$ & Parietal & R & 8,0 & Neg \\
$\# 163$ & Parietal & P & 2,0 & Neg \\
$\# 169$ & Temporal & P & 9,0 & Neg \\
$\# 171$ & Frontal & R & 17,0 & Pos \\
$\# 181$ & Occipital & R & 17,0 & Pos \\
$\# 206$ & Temporal & P & 27,0 & Neg \\
$\# 208$ & Temporal & R & 33,0 & Neg \\
$\# 210$ & Parietal & P & 10,5 & Pos \\
$\# 213$ & Frontal & R & 10,5 & Neg \\
\hline
\end{tabular}

deficient EGFRvIII ${ }^{+}$) (Fig. 3a). These GSCs are characterized by invasive or angiogenic in vivo behavior depending on whether EGFRwt (more invasive) or EGFRvIII (more angiogenic) is overexpressed [31]. Analysis of P3 cells and the two P3-derived cell lines by qRT-PCR revealed that all of them expressed VEGFR-1 as well as VEGFR-2 (Fig. 3b). VEGFR-1 level was significantly higher in EGFRvIII ${ }^{+}$than in P3 and EGFRwt ${ }^{+}$cells.

Strikingly, PIGF stimulated ECM invasion in all cell lines in a time-dependent manner while, as expected, only P3 and more significantly EGFRwt ${ }^{+}$cells responded to EGF (Fig. 3c, Additional file 4: Figure S4, Additional file 5: Figure S5 and Additional file 6: Figure S6). Consistently, treatment with D16F7 mAb inhibited invasion induced by PlGF, but it did not affect ECM invasion in response to EGF (Fig. 3c, Additional file 4: Figure S4, Additional file 5: Figure S5 and Additional file 6: Figure S6).

These results suggest that D16F7 may inhibit the aggressive behavior of GSCs expressing mutated EGFR.

D16F7 mAb inhibits VEGFR-1 auto-phosphorylation, intracellular signal transduction and ECM invasion in VEGFR-1 transfected GBM cells

Despite the presence of a conserved kinase domain containing an ATP binding site in VEGFR-1, ligand stimulation of the receptor results in only minor tyrosine phosphorylation in vitro and in vivo [43]. Indeed, the weak kinase activity of the receptor has posed challenges to studying features of VEGFR-1 signal transduction. To investigate the ability of D16F7 to affect signal transduction in GBM cells, we over-expressed the human VEGFR-1 membrane form in U87 expressing little endogenous VEGFR-1 protein. Cells transfected with control or VEGFR-1 cDNA-containing vectors were subsequently analyzed by RT-PCR (Fig. 4a) and Western blotting (Fig. 4b). For further experiments to assess the influence of D16F7 on signal transduction, the clone exhibiting the greatest VEGFR-1 protein expression was tested (i.e., U87-MF24). The Tyr 1213 residue in VEGFR-1 is regarded as one of the major autophosphorylation sites responsible for activation of intracellular signaling pathways $[44,45]$. Accordingly, we investigated whether receptor stimulation by its ligands (VEGF-A and PlGF) resulted in Tyr 1213 phosphorylation in transfected cells and whether D16F7 could inhibit this effect. Exposure of U87-MF24 (Fig. 4c) cells to VEGF-A or PIGF for 10 min induced robust VEGFR-1 kinase activity, as indicated by a marked increase of protein phosphorylation at Tyr 1213, and D16F7 reduced receptor auto-phosphorylation in a dose-dependent manner. VEGFR-1 activation by VEGF-A or PIGF in normal cells (e.g., endothelial cells, fibroblasts, monocytes) stimulates Erk $1 / 2$ of the MAPK signaling pathway $[3,16]$, which, in turn, promotes tumor cell invasion and 

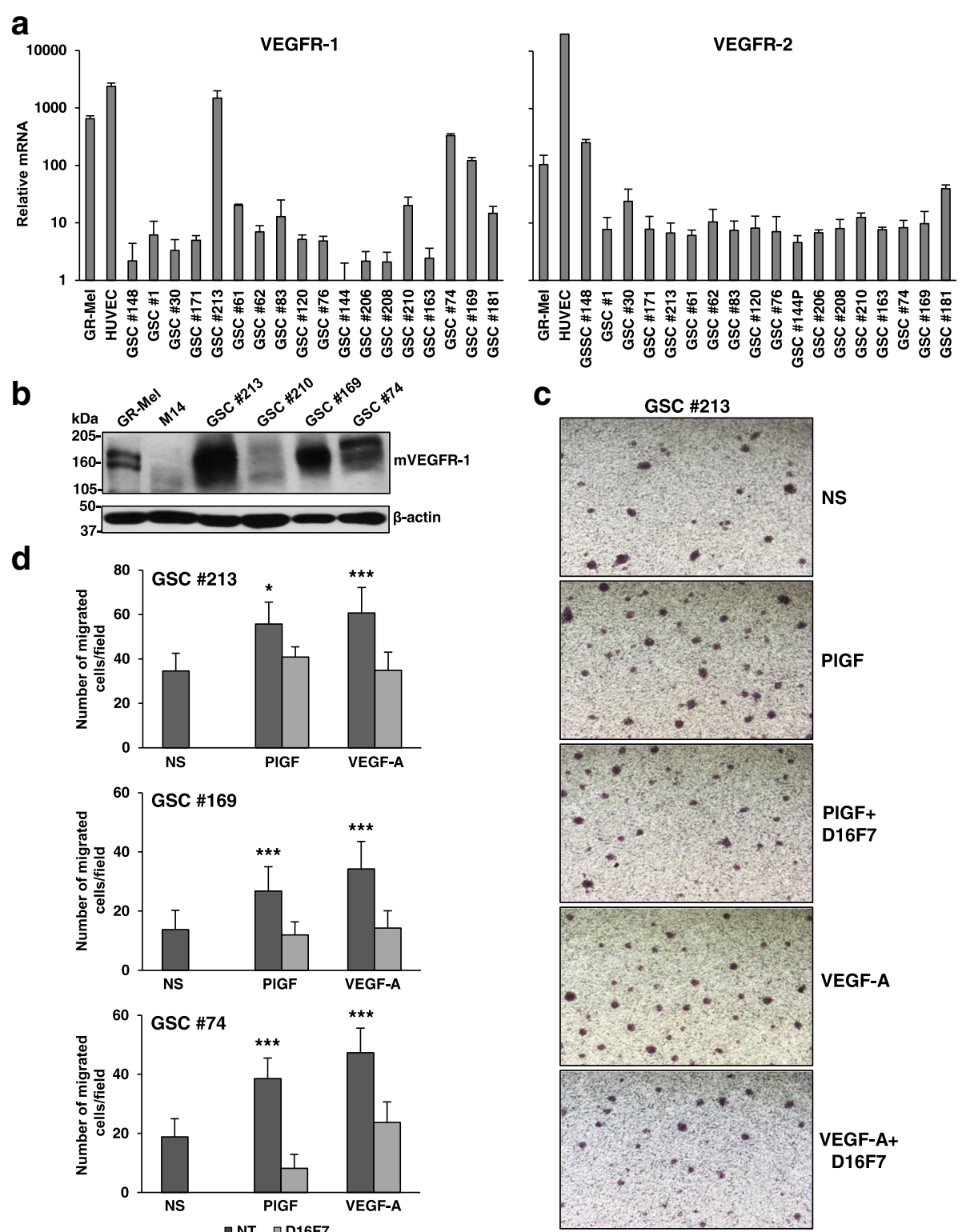

Figure 2

Fig. 2 D16F7 inhibitory effects on VEGF-A or PIGF-induced migration of GSCs. a Detection of VEGFR-1 and VEGFR-2 transcripts in GSC lines was performed by qRT-PCR. Results indicate relative mRNA expression and are the mean \pm SD of three independent determinations. $\mathbf{b}$ VEGFR-1 protein levels were analyzed by Western blotting using $\beta$-actin detection as loading control. HUVEC and M14 cells were used as positive and negative controls, respectively. c Migration of GSCs in response to PIGF or VEGF-A in the absence or in the presence of $5 \mathrm{\mu g} / \mathrm{ml} \mathrm{D16F7}$ was analyzed as described in Fig. 1c legend. Photographs from a representative experiment out of three with \#213 cells are shown (40x magnification). $\mathbf{d}$ Histograms represent the mean \pm SD $(n=3)$ of migrated cells/microscopic field. Results of statistical analysis using one-way ANOVA, followed by Bonferroni's post-test were as follows: in \#213, PIGF vs NS

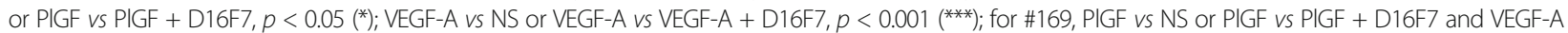
vs NS or VEGF-A vs VEGF-A + D16F7, $p<0.001$ (***); in \#74, PIGF vs NS or PIGF vs PIGF + D16F7 and VEGF-A vs NS or VEGF-A vs VEGF-A + D16F7, $p<0.001$ ${ }^{(* * *)}$. Differences between NS and PIGF + D16F7 or VEGF-A + D16F7 were not statistically significant

migration [46]. Accordingly, we investigated whether VEGF-A- or PlGF-induced receptor auto-phosphorylation at Tyr 1213 in U87-MF24 cells was accompanied by Erk1/ 2 phosphorylation, and whether D16F7 could reduce Erk1/2 activation. Results revealed that D16F7 markedly inhibited Erk1/2 phosphorylation stimulated by both ligands (Fig. 4c). Quantitative results are summarized as percentage inhibition of VEGFR-1 or Erk1/2 phosphorylation achieved after treatment with D16F7, calculated across three independent experiments (Fig. 4d).

VEGFR-1 over-expression in U87-MF24 cells highly stimulated ECM invasion triggered by PlGF and 


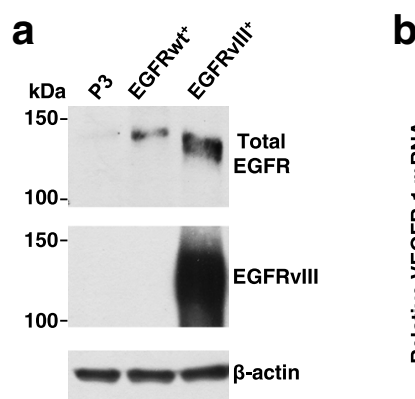

b

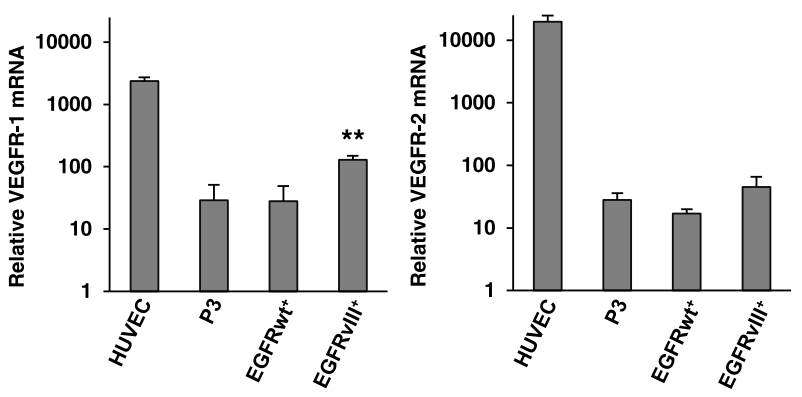

C
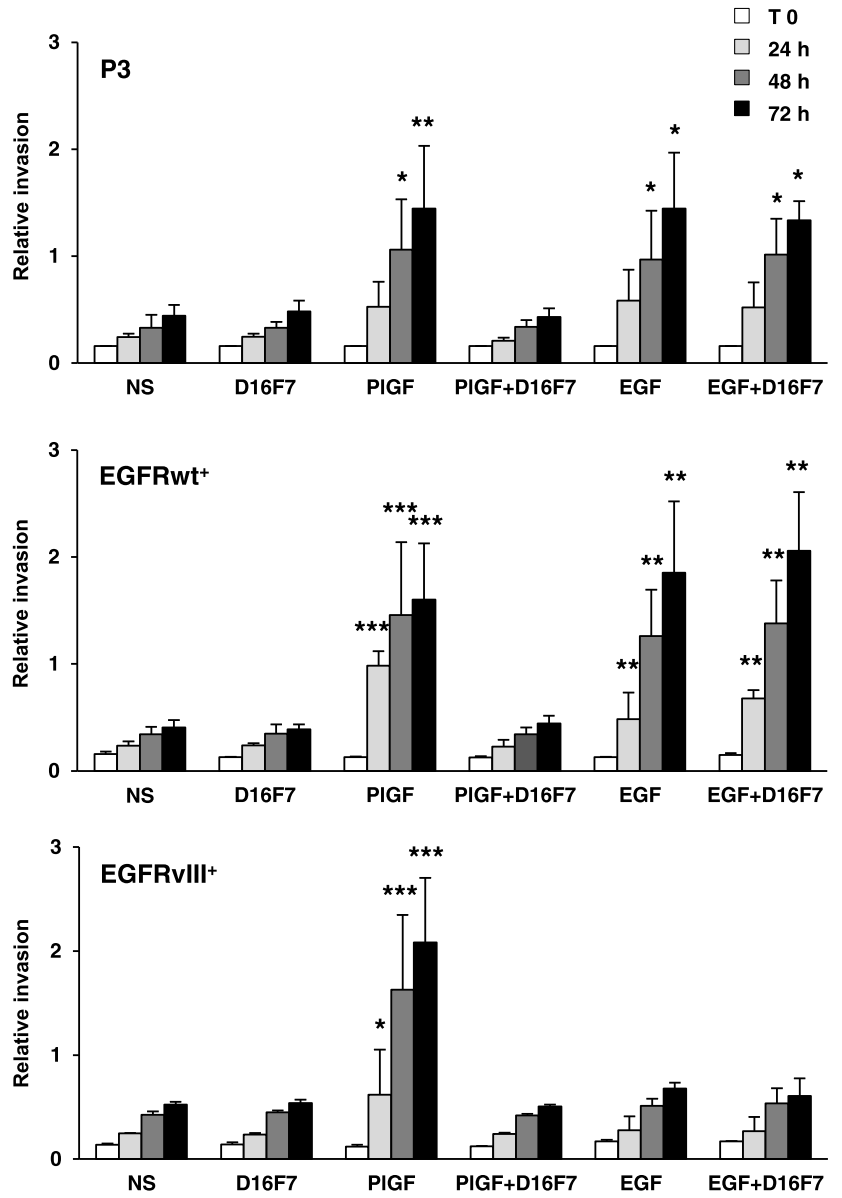

Fig. 3 D16F7 inhibits ECM invasion of P3, EGFRwt ${ }^{+}$and EGFRv III ${ }^{+}$GSCs that express VEGFR-1. a EGFR or mutated EGFRvIll protein levels were analyzed by Western blotting using $\beta$-actin detection as loading control. $\mathbf{b}$ Detection of VEGFR-1 and VEGFR-2 transcripts was performed by qRT-PCR. Results indicate relative mRNA expression and are the mean \pm SD of three independent determinations. EGFRvill ${ }^{+} v s$ P3 and EGFRwt ${ }^{+}$cells, $p<0.01$ (**). $\mathbf{c}$ For spheroid invasion assay cells were embedded in matrigel in the absence or presence of D16F7 $(10 \mu \mathrm{g} / \mathrm{ml})$ and PIGF or EGF. Data are the mean \pm SD $(n=5-10)$ relative invasion evaluated as described in Fig. 1d legend. Results of statistical analysis using one-way ANOVA, followed by Bonferroni's post-

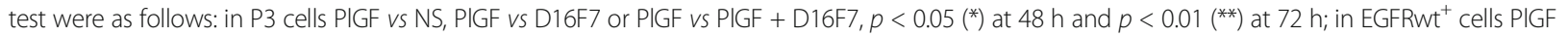

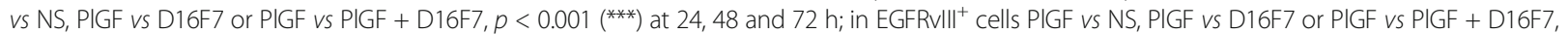
$p<0.05\left(^{*}\right)$ at $24 \mathrm{~h}$ and $p<0.001\left(^{* *}\right)$ at 48 and $72 \mathrm{~h}$. In all cell lines differences between NS and D16F7 or PIGF + D16F7 or between EGF and

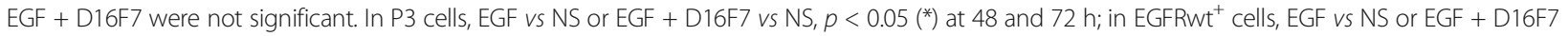
vs NS, $\left.p<0.01{ }^{* *}\right)$ at all time points 
a

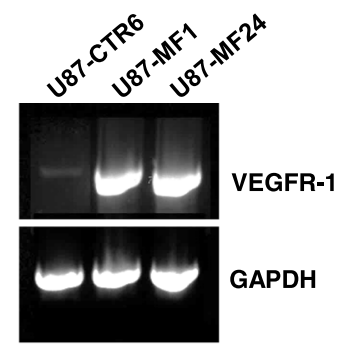

C
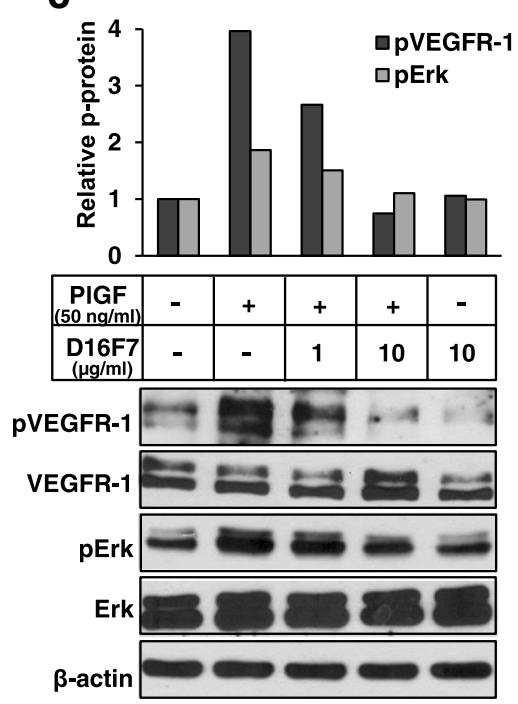

b

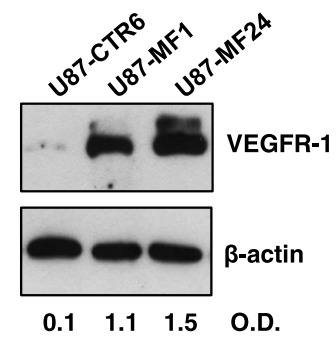

d

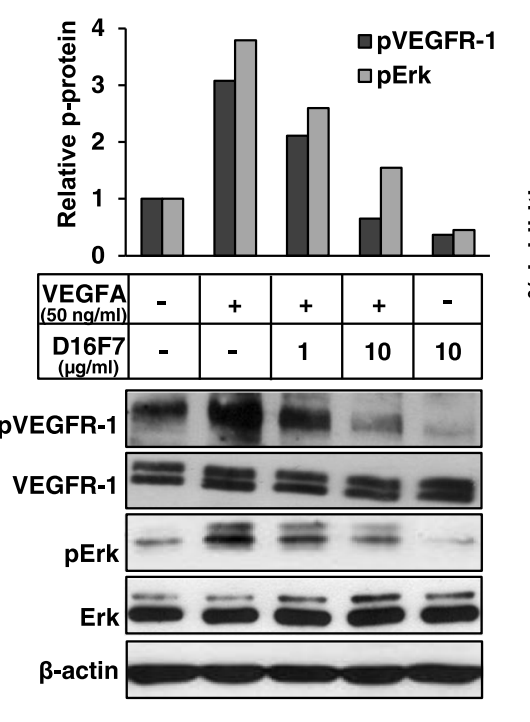

घD16F7 $1 \mu \mathrm{g} / \mathrm{ml} \quad$ QD16F7 $10 \mu \mathrm{g} / \mathrm{ml}$

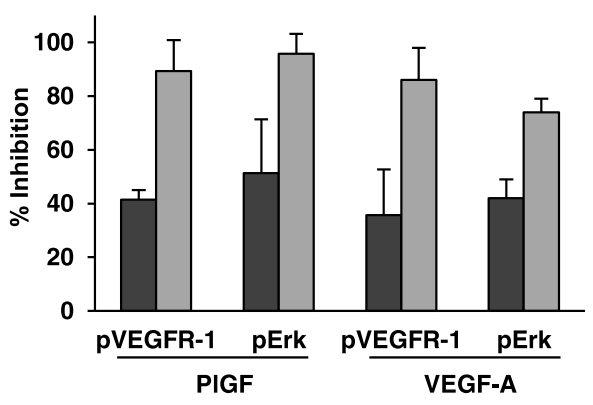

e
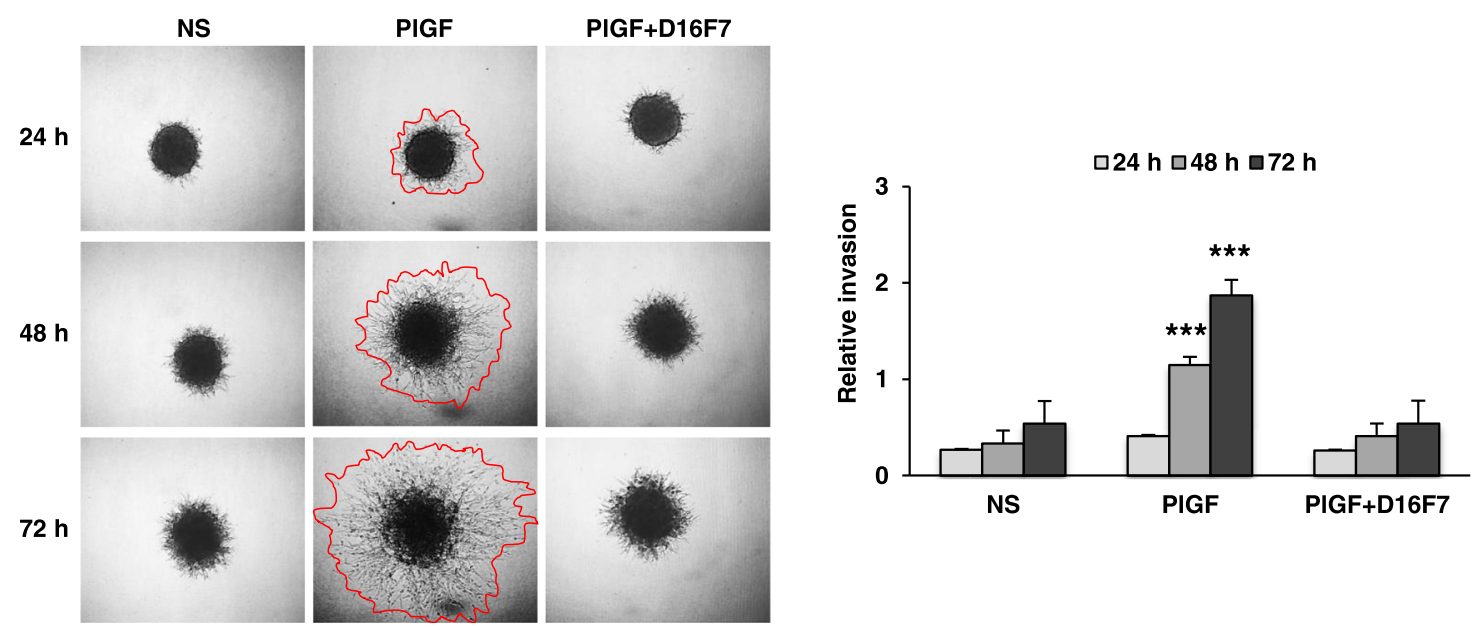

Fig. 4 (See legend on next page.) 


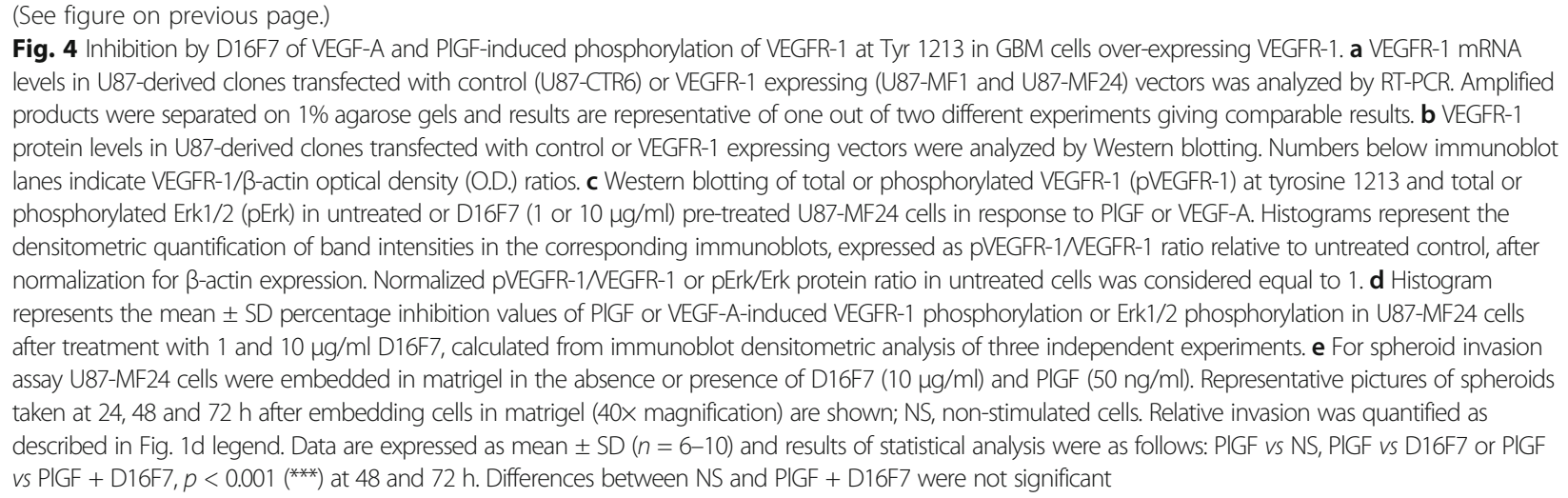

inhibition of PlGF-induced signaling by D16F7 resulted in abrogation of ECM invasion (Fig. 4e).

\section{Discussion}

In the present study we demonstrate for the first time that the novel anti-VEGFR-1 mAb D16F7, which diminishes receptor activation by VEGF-A and PlGF, inhibits chemotaxis and ECM invasion of human GBM and patient-derived GSC lines.

Our data suggest that VEGFR-1 itself can transmit signals that promote GBM cell invasiveness. Importantly, since D16F7 does not reduce VEGFR-1 interaction with its ligands while inhibiting receptor homodimerization, the $\mathrm{mAb}$ is considered to display inhibitory effects on VEGFR-1 activation in a non-competitive fashion [15]. Moreover, D16F7 does not hamper soluble VEGFR-1 ability to act as decoy receptor for VEGF-A and PlGF. This is particularly important considering the role of the soluble receptor in controlling tumor progression. In fact, in GBM low soluble VEGFR-1/VEGF-A ratio has been related to higher aggressiveness compared with astrocytomas [47].

Characterization of GBM lines showed that VEGF-A and PlGF are secreted by most of the cell lines tested, suggesting that an autocrine loop may occur in VEGFR1 expressing GBMs through activation of the receptor tyrosine kinase activity, in accordance with a previous study [39]. Indeed, since we found that VEGFR-1 is frequently detected in GBM specimens, D16F7 is expected to interrupt the autocrine loop that favors tumor aggressiveness.

Although required for inflammatory reactions associated with tumor growth and metastasis and for monocyte migration $[48,49]$, VEGFR-1 kinase activity is weakly induced upon ligand binding and receptor signaling has not been fully elucidated in tumor cells [43]. Potential tyrosine phosphorylation sites have been identified in VEGFR-1 $[17,44]$ and their role in receptor activation in GBM has been only recently investigated [50]. Tyrosine 1213, which is regarded as the main auto-phosphorylation site responsible for activation of intracellular pathways $[9,44,45]$, became phosphorylated in a highly VEGFR-1-expressing GBM cell line upon exposure to exogenous VEGF-A or PlGF [50]. In our study with U87-derived cells overexpressing VEGFR-1, exposure to VEGF-A or PIGF causes substantial receptor phosphorylation at tyrosine 1213 and pre-treatment with D16F7 prevents VEGFR-1 autophosphorylation in response to both ligands. Conversely, it has been reported that an anti-PlGF antibody only partially affected growth factor-induced VEGFR-1 autophosphorylation at this amino acid residue [50]. Therefore, our data strongly suggest that blockage of VEGFR-1 activity is more efficiently achieved using D16F7 mAb, which avoids receptor activation by both VEGF-A and PIGF. Moreover, in our model VEGFR-1 autophosphorylation is followed by downstream phosphorylation of Erk $1 / 2$ that is counteracted by D16F7 treatment.

Analysis of VEGFR-1 in GSC lines indicates a quite variable expression of the receptor. In particular, 17\% (3 out of 18) of the GSCs tested demonstrate high levels of VEGFR-1 transcript that result in remarkable amounts of the corresponding protein detected on immunoblot. In this context, our results are in line with a recent study in a limited number of patient-derived GSC samples showing VEGFR-1 staining by immunocytochemistry analysis [40].

The specificity of D16F7 against the chemotactic and invasive response to VEGF-A and PIGF was confirmed by the lack of antibody activity against cells responding to ligands that do not bind VEGFR-1 (i.e. EGF). Meanwhile, D16F7 markedly inhibits VEGFR-1 ligand-induced motility of GSCs expressing mutant EGFR (i.e., \#74 and P3-derived EGFRvIII ${ }^{+}$GCSs) as well as GSCs over-expressing EGFRwt (i.e., P3-derived EGFRwt $^{+}$GSCs). Actually, GBM cells harboring EGFRvIII mutation have recently been found to possess an angiogenic phenotype in vivo due to upregulated secretion of VEGF-A compared with cells over- 
expressing EGFRwt, which instead showed an enhanced invasive behavior [31].

Tumor cell invasion, angiogenesis, and genetic intratumor heterogeneity are hallmarks of GBM that reflect major factors involved in treatment failure [51-54]. Indeed, EGFR amplification and mutation are invariably expressed in a heterogeneous manner, and the presence of EGFRvIII in a minor population of GBM cells has been shown to confer a more aggressive tumor phenotype through paracrine mechanisms [53]. It has recently been demonstrated that EGFR amplification is an early event in GBM development, while EGFRvIII subsequently emerges during disease progression to drive a more aggressive tumor that becomes dependent on angiogenesis for growth [31]. Moreover, studies performed in a large cohort of GBM patients have indeed shown that VEGFR-1 is detected in tumor vessels and at significantly higher levels compared with lower grade gliomas [55]. In this context, since D16F7 can interact with VEGFR-1 expressed by tumor cells as well as by endothelial cells, the advantage of D16F7 in the control of GBM growth is two-fold: the mAb may inhibit tumor cell invasion and angiogenesis.

VEGF-A and PIGF produced by GBM cells can also stimulate angiogenesis and induce accumulation of VEGFR-1-positive bone marrow-derived myeloid cells in glioma tissues [24]. These cells are involved in neovessel formation and ECM invasion by secreting MMP and angiogenic factors or other cytokines that promote tumor cell survival $[24,56]$. Since D16F7 is able to suppress bone marrow mobilization of myeloid progenitors [15], this property may additionally contribute to restraining GBM progression.

\section{Conclusions}

The results presented indicate that VEGFR-1 is an appropriate target for reducing GBM aggressiveness and that D16F7-derived anti-VEGFR-1 humanized mAbs warrant further investigation for therapeutic intervention of GBM. Due to VEGFR-1 limited involvement in physiological angiogenesis, D16F7-derived molecules may synergize with agents targeting VEGFR-2/VEGF-A or EGFR/EGF without additional systemic toxicity.

\section{Additional files}

Additional file 1: Figure S1. Immunohistochemical analysis of VEGFR-1 expression in GBM tissue sections. Representative images are presented (25x magnification). VEGFR-1 immunostaining was scored as described in Table 1: score $1(<10 \%)$; score $2(11-25 \%)$; score $3(26-50 \%)$; score 4 (51-75\%); 5 (>75\%). (PDF $484 \mathrm{~kb}$ )

Additional file 2: Figure S2. VEGFR-1 immunostaining of endothelial and tumor cells in GBM tissue. Representative image from a GBM tissue section showing VEGFR-1 staining in endothelial cells (red arrows), along with tumor cells (black arrows). (PDF $60 \mathrm{~kb}$ )
Additional file 3: Figure S3. Specificity of D16F7 inhibitory activity on GBM cell migration in response to VEGFR-1 activation. Migration of U87 cells in response to PIGF $(50 \mathrm{ng} / \mathrm{ml})$ was evaluated in the presence of D16F7 or of a murine $\mathrm{lgG} 1$ control $\mathrm{mAb}(5 \mu \mathrm{g} / \mathrm{ml})$. Histogram represents the mean $( \pm S D)$ percentage inhibition of cell migration calculated from 3 independent determinations. (PDF $20 \mathrm{~kb}$ )

Additional file 4: Figure S4. Inhibition of ECM invasion by D16F7 cells in a spheroid assay with P3 cells. Representative pictures of spheroids taken at 24, 48 and $72 \mathrm{~h}$ after embedding P3 cells in matrigel (40x magnification) and referring to the experiment described in Fig. 3c legend. (PDF 255 kb)

Additional file 5: Figure S5. Inhibition of ECM invasion by D16F7 cells in a spheroid assay with EGFRwt ${ }^{+}$cells. Representative pictures of spheroids taken at 24, 48 and $72 \mathrm{~h}$ after embedding EGFRwt ${ }^{+}$cells in matrigel (40× magnification) and referring to the experiment described in Fig. $3 \mathrm{C}$ legend. (PDF $268 \mathrm{~kb}$ )

Additional file 6: Figure S6. Inhibition of ECM invasion by D16F7 cells in a spheroid assay with EGFRvIII ${ }^{+}$cells. Representative pictures of spheroids taken at 24,48 and $72 \mathrm{~h}$ after embedding EGFRv $\mathrm{II}^{+}$cells in matrigel (40x magnification) and referring to the experiment described in Fig. $3 \mathrm{C}$ legend. (PDF $198 \mathrm{~kb}$ )

\section{Abbreviations}

EGF: Epidermal growth factor; EGFR: Epidermal growth factor receptor; FBS: Fetal bovine serum; GBM: Glioblastoma; GSCs: Glioblastoma stem cells; HUVEC: Human umbilical vascular endothelial cells; mAbs: Monoclonal antibodies; MAPKs: Mitogen-activated protein kinases; MMP: Matrix metalloproteinase; MTS: 3-(4,5-dimethylthiazol-2-yl)-5-(3-carboxymethoxyphenyl) 2-(4-sulphophenyl)-2H-tetrazolium, inner salt; NBM: Neurobasal medium; PBS: Phosphate-buffered saline; PIGF: Placental growth factor; qRT-PCR: Quantitative real-time reverse transcriptase -polymerase chain reaction; VEGFR-1: Vascular endothelial growth factor receptor-1

\section{Acknowledgments}

The authors would like to thank Dr. Gabriella Maria Pia Ciotti ("Istituto di Farmacologia, Università Cattolica del Sacro Cuore", Rome, Italy) for technical assistance in immunohistochemistry analysis.

\section{Funding}

This work was supported by the Italian Association for Cancer Research (AIRC, Investigator Grant IG 2013 N. 14,042 to G.G.).

Availability of data and materials Not applicable.

\section{Authors' contributions}

MGA, LT, CC and PML performed proliferation, transfection, migration, invasion, ELISA and immunoblot experiments; FR, SD'A and PML performed qRT-PCR analysis; MS and EB provided tissue and pathological assistance; LL and PN performed immunohistochemistry analysis on GBM sections; LRV and RP generated and provided the GSC lines; EE, TD, HM and RB generated and provided the P3-derived GSC lines; GG and PML conceived the study; GG supervised the study and wrote the manuscript. All authors read and approved the final manuscript.

\section{Ethics approval and consent to participate}

The study with tumor samples obtained from patients was approved by the Ethical Committee of the Catholic University of Rome, Italy.

Consent for publication

Not applicable.

Competing interests

The authors declare that they have no competing interests.

\section{Publisher's Note}

Springer Nature remains neutral with regard to jurisdictional claims in published maps and institutional affiliations. 


\section{Author details}

'Department of Systems Medicine, University of Rome Tor Vergata, Via Montpellier 1, 00133 Rome, Italy. ${ }^{2}$ Laboratory of Molecular Oncology, "Istituto Dermopatico dell'Immacolata"-IRCCS, Via dei Monti di Creta, 104, 00167 Rome, Italy. ${ }^{3}$ sstituto di Farmacologia, Università Cattolica del Sacro Cuore, Largo Francesco Vito 1, 00168 Roma, Italia. ${ }^{4}$ Department of Experimental Medicine and Surgery, University of Rome Tor Vergata, Rome, Italy. ${ }^{5}$ Department of Genomic Medicine, University of Texas MD Anderson Cancer Center, Houston, TX, USA. ${ }^{6}$ INSERM U1029, University of Bordeaux, Pessac, France. ${ }^{7}$ Department of Biomedicine, University of Bergen, Bergen, Norway. ${ }^{8}$ Department of Hematology, Oncology and Molecular Medicine, "Istituto Superiore di Sanità" (ISS), Rome, Italy. 'Department of Neurosurgery, Università Cattolica del Sacro Cuore, Rome, Italy. ${ }^{10}$ UOC di Farmacologia, Fondazione Policlinico Universitario Agostino Gemelli, Largo Francesco Vito 1, 00168 Roma, Italia.

\section{Received: 10 July 2017 Accepted: 2 August 2017} Published online: 10 August 2017

\section{References}

1. Roskoski R Jr. VEGF receptor protein-tyrosine kinases: structure and regulation. Biochem Biophys Res Commun. 2008;375:287-91.

2. Takahashi S. Vascular endothelial growth factor (VEGF), VEGF receptors and their inhibitors for antiangiogenic tumor therapy. Biol Pharm Bull. 2011;34: 1785-8.

3. Cao Y. Positive and negative modulation of angiogenesis by VEGFR1 ligands. Sci Signal. 2009;2:re1.

4. Autiero M, Luttun A, Tjwa M, Carmeliet P. Placental growth factor and its receptor, vascular endothelial growth factor receptor-1: novel targets for stimulation of ischemic tissue revascularization and inhibition of angiogenic and inflammatory disorders. J Thromb Haemost. 2003;1:1356-70.

5. Fischer C, Mazzone M, Jonckx B, Carmeliet P. FLT1 and its ligands VEGFB and PIGF: drug targets for anti-angiogenic therapy? Nat Rev Cancer. 2008:8:942-56.

6. Ferrara N, Gerber HP, LeCouter J. The biology of VEGF and its receptors. Nat Med. 2003;9:669-76.

7. Cao Y, Chen H, Zhou L, Chiang MK, Anand-Apte B, Weatherbee JA, et al. Heterodimers of placenta growth factor vascular endothelial growth factor endothelial activity, tumor cell expression, and high affinity binding to Flk-1/KDR. J Biol Chem. 1996;271:3154-62.

8. Cudmore MJ, Hewett PW, Ahmad S, Wang KQ, Cai M, Al-Ani B, et al. The role of heterodimerization between VEGFR-1 and VEGFR-2 in the regulation of endothelial cell homeostasis. Nat Commun. 2012;3:972.

9. Anisimov A, Leppänen VM, Tvorogov D, Zarkada G, Jeltsch M, Holopainen T, et al. The basis for the distinct biological activities of vascular endothelial growth factor receptor-1 ligands. Sci Signal. 2013;6:ra52.

10. Li X. VEGF-B: a thing of beauty. Cell Res. 2010;20:741-4.

11. Kim KJ, Cho CS, Kim WU. Role of placenta growth factor in cancer and inflammation. Exp Mol Med. 2012:44:10-9.

12. Dewerchin M, Carmeliet P. PIGF: a multitasking cytokine with diseaserestricted activity. Cold Spring Harb Perspect Med. 2012;2.

13. Wu Y, Zhong Z, Huber J, Bassi R, Finnerty B, Corcoran E, et al. Anti-vascular endothelial growth factor receptor-1 antagonist antibody as a therapeutic agent for cancer. Clin Cancer Res. 2006;12:6573-84.

14. Schwartz JD, Rowinsky EK, Youssoufian H, Pytowski B, Wu Y. Vascular endothelial growth factor receptor-1 in human cancer: concise review and rationale for development of IMC-18F1 (human antibody targeting vascular endothelial growth factor receptor-1). Cancer. 2010;116:1027-32.

15. Graziani G, Ruffini F, Tentori L, Scimeca M, Dorio AS, Atzori MG, et al. Antitumor activity of a novel anti-vascular endothelial growth factor receptor-1 monoclonal antibody that does not interfere with ligand binding. Oncotarget. 2016;7:72868-85.

16. Tchaikovski $\mathrm{V}$, Fellbrich $\mathrm{G}$, Waltenberger J. The molecular basis of VEGFR-1 signal transduction pathways in primary human monocytes. Arterioscler Thromb Vasc Biol. 2008;28:322-8.

17. Autiero M, Waltenberger J, Communi D, Kranz A, Moons L, Lambrechts D, et al. Role of PIGF in the intra- and intermolecular cross talk between the VEGF receptors Flt1 and Flk1. Nat Med. 2003:9:936-43.

18. He J, Shen N, Huang X. Thyroid carcinoma cells produce PLGF to enhance metastasis. Tumour Biol. 2015;36:8601-7.

19. Higa GM, Abraham J. Biological mechanisms of bevacizumab-associated adverse events. Expert Rev Anticancer Ther. 2009;9:999-1007.
20. Das S, Marsden PA. Angiogenesis in glioblastoma. N Engl J Med. 2013;369: 1561-3.

21. Plate $\mathrm{KH}$, Scholz A, Dumont DJ. Tumor angiogenesis and anti-angiogenic therapy in malignant gliomas revisited. Acta Neuropathol. 2012;124:763-75.

22. Stupp R, Mason WP, van den Bent MJ, Weller M, Fisher B, Taphoorn MJ, et al. European Organisation for Research and Treatment of Cancer brain tumor and radiotherapy groups; National Cancer Institute of Canada clinical trials group. Radiotherapy plus concomitant and adjuvant temozolomide for glioblastoma. N Engl J Med. 2005;352:987-96.

23. Yan Y, Xu Z, Dai S, Qian L, Sun L, Gong Z. Targeting autophagy to sensitive glioma to temozolomide treatment. J Exp Clin Cancer Res. 2016;35:23.

24. Kerber M, Reiss Y, Wickersheim A, Jugold M, Kiessling F, Heil M, et al. Flt-1 signaling in macrophages promotes glioma growth in vivo. Cancer Res. 2008;68:7342-51.

25. Niyazi M, Harter PN, Hattingen E, Rottler M, von Baumgarten L, Proescholdt $M$, et al. Bevacizumab and radiotherapy for the treatment of glioblastoma: brothers in arms or unholy alliance? Oncotarget. 2016;7:2313-28.

26. Lisi L, Ciotti GM, Braun D, Kalinin S, Currò D, Dello Russo C, et al. Expression of iNOS, CD163 and ARG-1 taken as M1 and M2 markers of microglial polarization in human glioblastoma and the surrounding normal parenchyma. Neurosci Lett. 2017;645:106-12.

27. Pallini R, Ricci-Vitiani L, Banna GL, Signore M, Lombardi D, Todaro M, et al. Cancer stem cell analysis and clinical outcome in patients with glioblastoma multiforme. Clin Cancer Res. 2008;14:8205-12.

28. Ciceroni C, Bonelli M, Mastrantoni E, Niccolini C, Laurenza M, Larocca LM, et al. Type-3 metabotropic glutamate receptors regulate chemoresistance in glioma stem cells, and their levels are inversely related to survival in patients with malignant gliomas. Cell Death Differ. 2013;20:396-407.

29. Wu B, Sun C, Feng F, Ge M, Xia L. Do relevant markers of cancer stem cells CD133 and nestin indicate a poor prognosis in glioma patients? A systematic review and meta-analysis. J Exp Clin Cancer Res. 2015;34:44.

30. Tentori L, Ricci-Vitiani L, Muzi A, Ciccarone F, Pelacchi F, Calabrese R, et al. Pharmacological inhibition of poly(ADP-ribose) polymerase-1 modulates resistance of human glioblastoma stem cells to temozolomide. BMC Cancer. 2014;14:151.

31. Eskilsson E, Rosland GV, Talasila KM, Knappskog S, Keunen O, Sottoriva A, et al. EGFRvIll mutations can emerge as late and heterogeneous events in glioblastoma development and promote angiogenesis through Src activation. Neuro-Oncology. 2016;18:1644-55.

32. Orecchia A, Lacal PM, Schietroma C, Morea V, Zambruno G, Failla CM. Vascular endothelial growth factor receptor-1 is deposited in the extracellular matrix by endothelial cells and is a ligand for the a5ß1 integrin. J Cell Sci. 2003;116:3479-89.

33. Lacal PM, Failla CM, Pagani E, Odorisio T, Schietroma C, Falcinelli S, et al. Human melanoma cells secrete and respond to placenta growth factor and vascular endothelial growth factor. J Invest Dermatol. 2000;115:1000-7.

34. Ruffini F, Failla CM, Orecchia A, Bani MR, Dorio AS, Fortes C, et al. Expression of the soluble vascular endothelial growth factor receptor-1 in cutaneous melanoma: role in tumour progression. Br J Dermatol. 2011;164:1061-70.

35. Tentori L, Vergati M, Muzi A, Levati L, Ruffini F, Forini O, et al. Generation of an immortalized human endothelial cell line as a model of neovascular proliferating endothelial cells to assess chemosensitivity to anticancer drugs. Int J Oncol. 2005;27:525-35.

36. Lacal PM, Morea V, Ruffini F, Orecchia A, Dorio AS, Failla CM, et al. Inhibition of endothelial cell migration and angiogenesis by a vascular endothelial growth factor receptor-1 derived peptide. Eur J Cancer. 2008;44:1914-21.

37. Mu Z, Li H, Fernandez SV, Alpaugh KR, Zhang R, Cristofanilli M. EZH2 knockdown suppresses the growth and invasion of human inflammatory breast cancer cells. J Exp Clin Cancer Res. 2013;32:70.

38. Xu H, Chen Q, Wang H, Xu P, Yuan R, Li X, Bai L, Xue M. Inhibitory effects of lapachol on rat C6 glioma in vitro and in vivo by targeting DNA topoisomerase I and topoisomerase II. J Exp Clin Cancer Res. 2016:35:178.

39. Steiner $\mathrm{HH}$, Karcher S, Mueller MM, Nalbantis E, Kunze S, Herold-Mende C. Autocrine pathways of the vascular endothelial growth factor (VEGF) in glioblastoma multiforme: clinical relevance of radiation-induced increase of VEGF levels. J Neuro-Oncol. 2004;66:129-38.

40. D'Alessio A, Proietti G, Lama G, Biamonte F, Lauriola L, Moscato U, et al. Analysis of angiogenesis related factors in glioblastoma, peritumoral tissue and their derived cancer stem cells. Oncotarget. 2016;7:78541-56.

41. Yi Y, Hsieh IY, Huang X, Li J, Zhao W. Glioblastoma stem-like cells: characteristics, microenvironment, and therapy. Front Pharmacol. 2016;7:477.

42. Brennan CW, Verhaak RG, McKenna A, Campos B, Noushmehr H, Salama SR, et al. TCGA research network. TCGA research network. The somatic genomic landscape of glioblastoma. Cell. 2013;155:462-77. 
43. Claesson-Welsh L. VEGF receptor signal transduction - a brief update. Vasc Pharmacol. 2016;86:14-7.

44. Igarashi K, Isohara T, Kato T, Shigeta K, Yamano T, Uno I. Tyrosine 1213 of Flt-1 is a major binding site of Nck and SHP-2. Biochem Biophys Res Commun. 1998;246:95-9.

45. Yu Y, Hulmes JD, Herley MT, Whitney RG, Crabb JW, Sato JD. Direct identification of a major autophosphorylation site on vascular endothelial growth factor receptor Flt-1 that mediates phosphatidylinositol 3'-kinase binding. Biochem J. 2001;358:465-72.

46. Koch S, Tugues S, Li X, Gualandi L, Claesson-Welsh L. Signal transduction by vascular endothelial growth factor receptors. Biochem J. 2011;437:169-83.

47. Lamszus K, Ulbricht U, Matschke J, Brockmann MA, Fillbrandt R, Westphal M. Levels of soluble vascular endothelial growth factor (VEGF) receptor 1 in astrocytic tumors and its relation to malignancy, vascularity, and VEGF-A. Clin Cancer Res. 2003:9:1399-405.

48. Shibuya M. Vascular endothelial growth factor receptor-1 (VEGFR-1/Flt-1): a dual regulator for angiogenesis. Angiogenesis. 2006:9:225-30.

49. Kaplan RN, Psaila B, Lyden D. Bone marrow cells in the 'pre-metastatic niche': within bone and beyond. Cancer Metastasis Rev. 2006;25:521-9.

50. Szabo E, Schneider H, Seystahl K, Rushing EJ, Herting F, Weidner KM, Weller M. Autocrine VEGFR1 and VEGFR2 signaling promotes survival in human glioblastoma models in vitro and in vivo. Neuro-Oncology. 2016;18:1242-52.

51. Miletic H, Niclou SP, Johansson M, Bjerkvig R. Anti-VEGF therapies for malignant glioma: treatment effects and escape mechanisms. Expert Opin Ther Targets. 2009;13:455-68.

52. Onishi M, Ichikawa T, Kurozumi K, Date I. Angiogenesis and invasion in glioma. Brain Tumor Pathol. 2011;28:13-24.

53. Inda MM, Bonavia R, Mukasa A, Narita Y, Sah DW, Vandenberg S, et al. Tumor heterogeneity is an active process maintained by a mutant EGFRinduced cytokine circuit in glioblastoma. Genes Dev. 2010;24:1731-45.

54. Ylivinkka I, Sihto H, Tynninen O, Hu Y, Laakso A, Kivisaari R, et al. Motility of glioblastoma cells is driven by netrin-1 induced gain of stemness. J Exp Clin Cancer Res. 2017:36:9.

55. Baumgarten $P$, Blank AE, Franz $K$, Hattingen $E$, Dunst $M$, Zeiner $P$, et al. Differential expression of vascular endothelial growth factor $a$, its receptors VEGFR-1, -2 , and -3 and co-receptors neuropilin-1 and -2 does not predict bevacizumab response in human astrocytomas. Neuro-Oncology. 2016;18: 173-83.

56. Park K, Amano H, Ito Y, Kashiwagi S, Yamazaki Y, Takeda A, et al. Vascular endothelial growth factor receptor-1 (VEGFR-1) signaling enhances angiogenesis in a surgical sponge model. Biomed Pharmacother. 2016;78:140-9.

\section{Submit your next manuscript to BioMed Central and we will help you at every step:}

- We accept pre-submission inquiries

- Our selector tool helps you to find the most relevant journal

- We provide round the clock customer support

- Convenient online submission

- Thorough peer review

- Inclusion in PubMed and all major indexing services

- Maximum visibility for your research

Submit your manuscript at www.biomedcentral.com/submit
Biomed Central 